\title{
Gluco-incretins control insulin secretion at multiple levels as revealed in mice lacking GLP-1 and GIP receptors
}

\author{
Frédéric Preitner, ${ }^{1}$ Mark Ibberson, ${ }^{1}$ Isobel Franklin, ${ }^{2}$ Christophe Binnert, ${ }^{3}$ Mario Pende,${ }^{4}$ \\ Asllan Gjinovci, ${ }^{2}$ Tanya Hansotia, ${ }^{5}$ Daniel J. Drucker, ${ }^{5}$ Claes Wollheim, ${ }^{2}$ Rémy Burcelin, ${ }^{1}$ \\ and Bernard Thorens ${ }^{1,3}$
}

\author{
${ }^{1}$ Institute of Pharmacology and Toxicology, Lausanne, Switzerland \\ ${ }^{2}$ Division of Clinical Biochemistry, Department of Internal Medicine, University Medical Center, Geneva, Switzerland \\ ${ }^{3}$ Institute of Physiology, Lausanne, Switzerland \\ ${ }^{4}$ Friedrich Miescher Institute, Basel, Switzerland \\ ${ }^{5}$ Department of Medicine, Banting and Best Diabetes Center, Toronto General Hospital, University of Toronto, \\ Toronto, Ontario, Canada
}

The role of the gluco-incretin hormones GIP and GLP- 1 in the control of $\beta$ cell function was studied by analyzing mice with inactivation of each of these hormone receptor genes, or both. Our results demonstrate that glucose intolerance was additively increased during oral glucose absorption when both receptors were inactivated. After intraperitoneal injections, glucose intolerance was more severe in double- as compared to single-receptor $\mathrm{KO}$ mice, and euglycemic clamps revealed normal insulin sensitivity, suggesting a defect in insulin secretion. When assessed in vivo or in perfused pancreas, insulin secretion showed a lack of first phase in $\mathrm{Glp}-1 \mathrm{R}^{-/-}$but not in $\mathrm{Gipr}^{-/-}$mice. In perifusion experiments, however, first-phase insulin secretion was present in both types of islets. In double-KO islets, kinetics of insulin secretion was normal, but its amplitude was reduced by about $50 \%$ because of a defect distal to plasma membrane depolarization. Thus, gluco-incretin hormones control insulin secretion (a) by an acute insulinotropic effect on $\beta$ cells after oral glucose absorption (b) through the regulation, by GLP-1, of in vivo first-phase insulin secretion, probably by an action on extra-islet glucose sensors, and (c) by preserving the function of the secretory pathway, as evidenced by a $\beta$ cell autonomous secretion defect when both receptors are inactivated.

J. Clin. Invest. 113:635-645 (2004). doi:10.1172/JCI200420518.

\section{Introduction}

Insulin secretion is controlled by the pancreatic $\beta$ cell glucose sensor but also by sensors that are located at other anatomical sites and that send hormonal or nervous signals to the $\beta$ cells. The gut endocrine cells, which secrete the gluco-incretin hormones GIP and GLP-1 after absorption of nutrients, particularly glucose $(1,2)$, represent such a secondary control system. The glucoincretin hormones play different roles in the control of whole-body glucose homeostasis. Their best-described effect, however, is the potentiation of glucose-stimulat-

Received for publication November 11, 2003, and accepted in revised form December 16, 2003.

Address correspondence to: Bernard Thorens, Institute of Pharmacology and Toxicology, 27, rue du Bugnon, 1005 Lausanne, Switzerland. Phone: 41-21-692-53-90; Fax: 41-21-692-53-55; E-mail: Bernard.Thorens@ipharm.unil.ch. Mark Ibberson's present address is: Serono Pharmaceutical Research Institute, Geneva, Switzerland.

Mario Pende's present address is: INSERM U508, Hôpital Necker, Paris, France.

Rémy Burcelin's present address is: Centre Hospitalier Universitaire Rangueil, UMR 5018, Toulouse, France.

Conflict of interest: The authors have declared that no conflict of interest exists.

Nonstandard abbreviations used: area under the curve (AUC); Krebs-Ringer solution (KRBH); isobutylmethylxanthine (IBMX); intraperitoneal glucose tolerance test (IPGTT). ed insulin secretion $(3,4)$, an action that requires binding of the hormones to specific $\beta$ cell G-coupled receptors that activate the adenylyl cyclase pathway $(5,6)$. This insulinotropic effect, which is responsible for approximately $50 \%$ of the insulin secreted after meal absorption, becomes progressively blunted in the development of type 2 diabetes $(1,7)$ as a result of a decrease in the secretion of these hormones as well as a decreased response of the $\beta$ cells to their action (8).

Apart from the stimulation of insulin secretion, both GIP and GLP-1 have additional physiological effects as a result of expression of their receptors in several other tissues. Most notably, GIP may control fat metabolism, as suggested by the presence of its receptor in adipose tissue. GLP-1, on the other hand, has been studied in greater detail because of the preservation of its insulinotropic effect in type 2 diabetes, thus suggesting its potential use in the treatment of this disease $(9,10)$. Clinical trials have thus shown that in addition to stimulating insulin secretion and normalizing blood glucose and hemoglobin $\mathrm{A}_{1 \mathrm{C}}, \mathrm{GLP}-1$ also reduces the rate of gastric emptying and increases satiety, thus leading to a reduction in body weight (11). Studies in rodents have further described that GLP- 1 can increase $\beta$ cell mass, probably through a combination of transcriptional activation of key genes involved in $\beta$ cell differentiation and 
function, such as $P d x-1$, Glut2, glucokinase, and insulin $(12-16)$, and by providing protection against apoptosis (17). Recently we have also demonstrated that an important site of GLP-1 action is on the hepatoportal glucose sensor. This sensor is activated when a glucose gradient is established between the portal and peripheral blood, for instance after meal absorption, or experimentally by direct portal vein glucose injection. Using this last protocol, we demonstrated that the activated sensor increases glucose clearance by peripheral tissues through a mechanism independent of insulin action $(18,19)$. Glucose detection by this sensor requires, in addition to GLUT2 (20), the presence of an activated GLP-1 receptor, as demonstrated by the use of $\mathrm{KO}$ mice lacking the GLP-1 receptor or by infusion of the GLP-1 antagonist exendin-(9-39) in the portal vein, which completely prevents its activation (21).

The physiological importance of the gluco-incretin receptors has been further studied by gene inactivation in the mouse. KO mice lacking the GIP receptor showed impaired tolerance to oral glucose load but not to intraperitoneal glucose injection (22). High-fat feeding for 3 weeks induced a marked increase in the glycemic excursions after meal absorption. However, inactivation of this receptor gene protected mice from obesity induced by a high-fat diet, and transfer of this mutation in $o b / o b$ mice reduced their body weight (23). KO mice lacking the GLP-1 receptor had a marked intolerance to oral glucose absorption but only a mild intolerance to intraperitoneal glucose injection and displayed normal feeding behavior (24). However, in these mice, absence of GLP-1 receptors was compensated by upregulation of both GIP plasma levels and GIP action on pancreatic islets. Also, lack of GIP receptor led to higher sensitivity to GLP-1 in pancreatic islets (25-27). Thus, inactivation of each receptor caused only mild impairment in whole-body glucose and energy homeostasis, which may be due to compensatory overexpression of the other incretin hormone. Therefore, inactivation of both receptors should lead to a stronger defect in whole-body glucose homeostasis.

Here, we studied mice with inactivation of either each gluco-incretin receptor or both. We show that these hormones control insulin secretion through three different mechanisms. First, they have additive insulinotropic effects on $\beta$ cells during oral glucose tolerance tests. Second, in the absence of the GLP-1 receptor, there is suppression of the first phase of insulin secretion measured in vivo, but not in the isolated islets, indicating a role for this receptor in the function of glucose sensors that are located outside the endocrine pancreas and that control first-phase secretion. Third, absence of both receptors causes a $\beta$ cell autonomous insulin secretion defect at a site distal to plasma membrane depolarization.

\section{Methods}

Generation of KO mice lacking either the GIP receptor or both the GLP-1 and GIP receptors. The mouse GIP recep- tor gene was cloned from a 129/SV mouse genomic library (Stratagene, La Jolla, California, USA) using human GIPR cDNA as a probe (28) and mapped by restriction enzyme analysis (see Figure 1). The targeting vector was made by cloning a $4.5-\mathrm{kb}$ BglII fragment of sequence $5^{\prime}$ of the mouse Gipr gene and a 3.5$\mathrm{kb}$ AflII-BamHI fragment covering exons 6-10 into pBluescriptKS (Stratagene) and inserting a neomycinresistance cassette in place of the first six exons. Two copies of the HSVtk cassette were cloned $5^{\prime}$ of the BglII fragment. E14 ES cells were transfected as described (29), and positive clones were identified by Southern blotting using HindIII-digested genomic DNA and a 200-bp StuI-NheI probe external to the vector. Chimeric C57BL/6 mice were obtained by morula aggregation as described (30), and subsequent

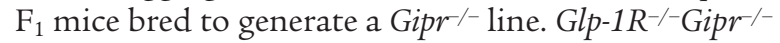

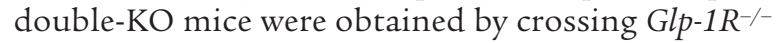
and Gipr-/- mice and subsequently crossing the dou-

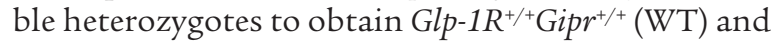
Glp-1 $R^{-1-}$ Gipr $^{-1}$ (double-KO) mice on the same C57BL/6 $\times$ SV129 hybrid background. Both single- and double$\mathrm{KO}$ mice were obtained in the expected mendelian ratios. Glp-1 $1 R^{-/-} \mathrm{Gipr}^{-/-}$mice and their single-KO con-

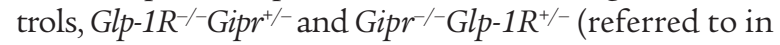
the text as Glp-1 $R^{-/-}$and $\mathrm{Gipr}^{-/-}$mice, respectively),

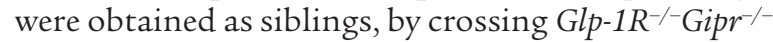

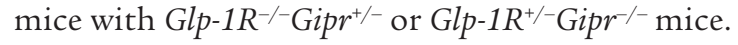

Mice were maintained on a 12 hours light/12 hours dark cycle, with free access to water and standard laboratory chow (Provimi Kliba, Penthalaz, Switzerland). Animals were treated in accordance with our Institutional Guidelines and with the authorization of the Service Vétérinaire Cantonal.

Glucose tolerance and insulin secretion in vivo. After a 16hour overnight fast, age- and sex-matched 14- to 16week-old mice received glucose by intragastric gavage ( $3 \mathrm{mg} / \mathrm{g}$, as a $66 \%$ solution) or by intraperitoneal injections $(1 \mathrm{mg} / \mathrm{g}$, as a $10 \%$ solution). Blood samples were obtained from tail-tip bleedings, and blood glucose levels were measured with a Glucometer (Glucotrend Premium; Boehringer Mannheim GmbH, Mannheim, Germany). Glycemic areas under the curve (AUCs) were measured from time 0 to 120 minutes, after subtraction of basal glycemia from each time point. Plasma insulin levels were determined by ELISA (Mercodia AB, Uppsala, Sweden).

For measurement of pancreatic insulin content, pancreata were quickly dissected, weighed, and homogenized in acid ethanol. Insulin was measured by RIA (Linco Research Inc., St. Charles, Missouri, USA). Pancreata were perfused in situ on mice starved overnight (31), with basal and stimulatory glucose concentrations of 1 and $16.7 \mathrm{mM}$, respectively. Secreted insulin was measured by RIA (30). Statistical analysis was based on the comparison of the AUCs for first and second phases of secretion from WT and mutant mice using a Student's $t$-test (two-tailed distribution, twosample equal variance). 

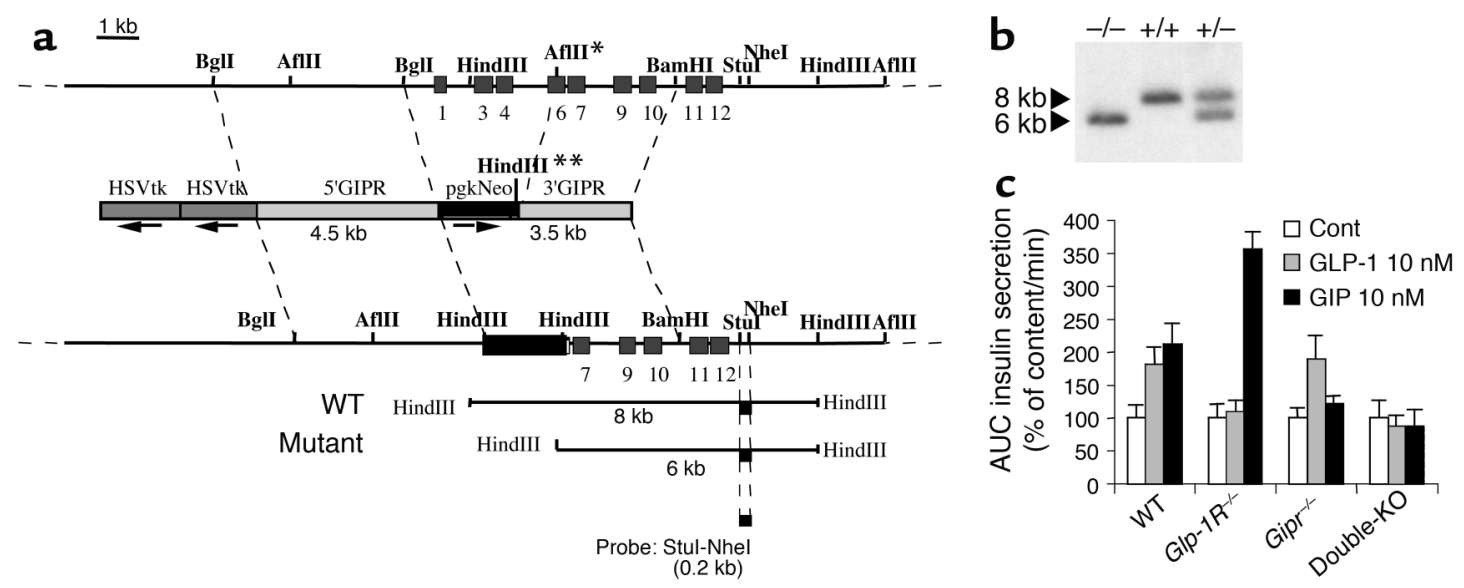

Figure 1

Generation of Gipr ${ }^{-1-}$ mice. (a) Diagram showing the mouse GIP-receptor gene, the GIP-receptor targeting vector, and the recombined allele. The genomic fragments diagnostic of homologous recombination using the external Stul-Nhel probe are shown at the bottom of the figure. Positions of exons are marked as light gray boxes. In the mutant allele the Aflll site denoted with * is replaced by a HindIII site on the 3' end of the pgkNeo gene (marked with ${ }^{*}$ ). In the targeting vector, the arrows indicate the transcriptional orientation of the selection genes. (b) Southern blot analysis of the recombined alleles in mouse genomic DNA using the Stul-Nhel probe. (c) Confirmation of receptor gene inactivation. Perifused isolated pancreatic islets from WT, Glp-1 $1 R^{-1-}$, Gipr ${ }^{-1}$, or double-KO mice were challenged with successive 10-minute stimulation periods to $11.1 \mathrm{mM}$ glucose, $2.8 \mathrm{mM}$ glucose, $11.1 \mathrm{mM}$ glucose + GLP-1 (10 nM), $2.8 \mathrm{mM}$ glucose, $11.1 \mathrm{mM}$ glucose + GIP (10 nM), and $2.8 \mathrm{mM}$ glucose. Total insulin responses, quantified as AUC, are normalized for each genotype to the insulin response at $11.1 \mathrm{mM}$ glucose alone, set at $100 \% . n=4$. Cont, control.

Insulin secretion and cAMP accumulation in isolated pancreatic islets. Islets were isolated by hand-picking after collagenase digestion of pancreas (32) and were maintained overnight in RPMI 1640 medium supplemented with $10 \%$ FCS, 10 mM HEPES, pH 7.4, 1 mM sodium pyruvate, $100 \mathrm{U} / \mathrm{ml}$ penicillin-streptomycin, $50 \mu \mathrm{M}$ $\beta$-mercaptoethanol, and $11 \mathrm{mM}$ glucose.

For perifusion experiments, batches of 30 islets were placed in parallel perifusion chambers at $37^{\circ} \mathrm{C}$ and perifused at a flow rate of $1 \mathrm{ml} / \mathrm{min}$ with a Krebs-Ringer solution (KRBH) containing $0.5 \% \mathrm{BSA}$. Islets were first equilibrated for 30 minutes in KRBH supplemented with $2.8 \mathrm{mM}$ glucose and then stimulated during 10minute periods in high glucose concentrations (11.1 or $16.7 \mathrm{mM}$ ) with chemicals as indicated. Fractions were collected every minute. At the end of each perifusion, islets were pelleted by centrifugation and lysed in acid ethanol for assessment of insulin content by RIA. Results are presented as insulin secreted $(\mathrm{ng} / \mathrm{ml})$ per minute normalized to islet insulin content.

For static incubations, islets were preincubated for 1 hour in $1 \mathrm{ml} \mathrm{KRBH}$ supplemented with $2.8 \mathrm{mM}$ glucose, in 12-well plates. Then, islets were transferred to new plates containing $1 \mathrm{ml} \mathrm{KRBH}$ supplemented with $16.7 \mathrm{mM}$ glucose and chemicals as indicated. For insulin measurements, batches of 10 islets were incubated for 15 minutes in the absence or presence of isobutylmethylxanthine (IBMX) $100 \mu \mathrm{M}$ and/or forskolin $10 \mu \mathrm{M}$. Insulin in media and islets was then measured as described before. For cAMP measurements, batches of 20 islets were incubated for 15 minutes in the presence of $250 \mu \mathrm{M}$ IBMX and were then lysed in ice-cold $0.1 \mathrm{M} \mathrm{HCl}$. cAMP was measured using a kit (Amersham Biosciences Europe $\mathrm{GmbH}$, Freiburg, Germany).

Statistical analysis. Data are expressed as mean \pm SE. Statistical analyses were performed using the Excell 2000 or Origin 6.0 (Microcal Software Inc., Northampton, Massachusetts, USA) software. Data were analyzed using unpaired $t$-test or one-way ANOVA.

\section{Results}

Generation of Gipr/- and Glp-1R-/-Gipr/- mice. We generated mice with inactivation of the Gipr gene by replacing exons 1-6 with a neomycin cassette (Figure 1a). Transmission of the mutant allele was confirmed by Southern blot analysis using a $3^{\prime}$ probe, external to the targeting vector (Figure 1b). We then intercrossed Gipr ${ }^{-1-}$ mice with

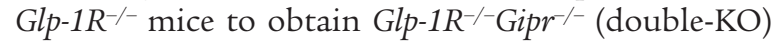
mice. Controls were derived from littermates of double$\mathrm{KO}$ mice and single-KO mice.

To confirm the absence of the hormone receptor from pancreatic islets of each set of mutants, we measured the insulin secretion from isolated islets incubated in the presence of either hormone. Figure $1 \mathrm{c}$ demonstrates that inactivation of each receptor led to suppression of the insulinotropic action of the respective hormone, and inactivation of both receptor genes abolished the effects of both hormones.

Double-KO mice were fertile and exhibited no gross behavioral abnormalities. Their body weight was similar to that of control mice, and their fed and fasted blood glucose concentrations were normal (Table 1). The plasma insulin levels of fasted females tended to be lower in the KO mice as compared to controls, although the difference sometimes did not reach statis- 
Table 1

Body weight, blood glucose, and plasma insulin levels in experimental mice 3-4 months old

\begin{tabular}{|c|c|c|c|c|}
\hline & WT & $\mathrm{Glp}-1 \mathrm{R}^{-/-} \mathrm{Gipr}^{+/-}$ & 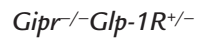 & Double-KO \\
\hline \multicolumn{5}{|l|}{ Body weight (g) } \\
\hline Males & $31.1 \pm 0.6(11)$ & $28.9 \pm 0.6(12)$ & $28.0 \pm 0.6(19)$ & $28.1 \pm 0.6(17)$ \\
\hline Females & $21.9 \pm 0.3(10)$ & $20.5 \pm 0.7(11)$ & $22.1 \pm 0.7(9)$ & $21.0 \pm 0.7(11)$ \\
\hline \multicolumn{5}{|c|}{ Blood glucose (mM) } \\
\hline Males (fasted) & $4.7 \pm 0.2(11)$ & $4.7 \pm 0.2(11)$ & $4.6 \pm 0.2(9)$ & $4.6 \pm 0.2(10)$ \\
\hline Males (fed) & $6.6 \pm 0.5(7)$ & N.D. & N.D. & $7.1 \pm 0.4(5)$ \\
\hline Females (fasted) & $4.5 \pm 0.3(11)$ & $4.7 \pm 0.3(7)$ & $4.5 \pm 0.3(13)$ & $4.7 \pm 0.4(15)$ \\
\hline Females (fed) & $8.9 \pm 0.3(11)$ & N.D. & N.D. & $9.1 \pm 0.4(12)$ \\
\hline
\end{tabular}

Numbers of experimental animals are given in parentheses. N.D., no data.

tical significance (see Figures $2 \mathrm{~b}$ and $3 \mathrm{~d}$ ). In males no statistically significant differences were observed in plasma insulin levels in the fasted state (Figure 2d).

Double-KO mice are intolerant to oral glucose. To evaluate the impact of gluco-incretin receptor gene inactivation on disposal of a glucose load, we performed oral glucose tolerance tests. Female mice with a single-receptor gene inactivation showed glucose intolerance as revealed by a significant increase in the AUC of the glucose tolerance test (AUC glucose) (Figure 2a). Female mice with doublereceptor $\mathrm{KO}$ displayed greater intolerance, with an AUC glucose approximately twice that of WT and $40-50 \%$ higher than in singleKO mice (Figure 2a). Glucose intolerance in single-KO mice was associated with a $34-43 \%$ lower plasma insulin level measured at 15 minutes after glucose injection compared to WT control mice (Figure 2b). Double-KO mice exhibited an even lower insulin response (-57\% vs. WT; -24 to $-34 \%$ vs. single-KO mice) (Figure $2 b$ ).

In male mice, glucose intolerance was less marked, with AUC glucose for double-KO mice increased by $17-40 \%$ as compared to single-KO mice, and by $50 \%$ as compared to WT mice (Figure 2c). The corresponding insulin responses were significantly blunted, with a $60 \%$ reduction as compared to WT mice and a $40 \%$ reduction as compared to the GLP-1 receptor KO mice (Figure 2d). These data indicate an additive insulinotropic action of GIP and GLP-1 during an oral glucose load. The incretin effect of each hormone seemed to be of similar magnitude in females when comparing the AUC glucose and

\section{Figure 2} ${ }^{\# \# P}<0.01,{ }^{\dagger} P<0.005$ vs. double-KO.
AUC insulin in single-receptor $\mathrm{KO}$ mice. In light of these criteria, the incretin effect of GIP was more important than that of GLP-1 in male mice. Intraperitoneal glucose intolerance and impaired first-phase insulin secretion in double-KO mice. Oral, but not intraperitoneal, glucose administration induces the secretion of glucoincretin hormones. To evaluate whether single or combined suppression of the GIP and GLP-1 receptors also led to altered glucose tolerance and insulin secretion when secretion of these hormones was not stimulated, we performed intraperitoneal glucose tolerance tests (IPGTTs). Male mice with single- and double-receptor gene KO showed normal basal glycemia as well as normal glucose tolerance after intraperitoneal glucose injection, at both 14-16 and 40 weeks of age (Figure 3 , a and b). Thus glucose tolerance was not impaired in male $\mathrm{KO}$ mice.

In 14- to 16-week-old single- and double-KO female mice, basal glycemia was normal (Figure 3c). However,
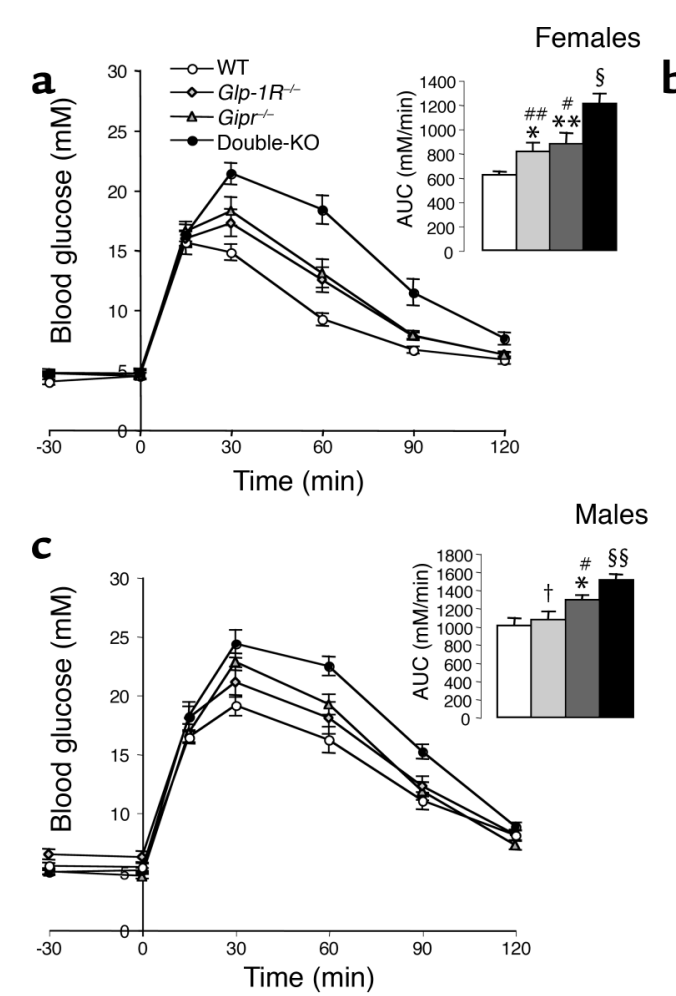

Oral glucose tolerance tests ( $3 \mathrm{mg} / \mathrm{g}$ ) in 3- to 4-month-old mice. (a and c) Glycemic excursions for (a) female WT $(n=11), G^{\prime p-1 R^{-/-}}(n=6), \mathrm{Gipr}^{-/-}(n=9)$, and double-KO mice $(n=11)$ and for (c) male mice $(n=12-19)$. Insets: quantification of the glycemic excursions as AUC. ( $b$ and $\mathbf{d})$ Basal and peak plasma insulin levels 15 minutes after gavage for (b) female WT $(n=12)$, Glp-1 $1 R^{-1-}(n=17)$, Gipr ${ }^{-1-}(n=12)$, and double-KO mice $(n=9)$, and for (d) males $(n=9-13)$. Data pooled from two to four separate experiments are expressed as means \pm SE. ${ }^{*} P<0.05$, ${ }^{*} P<<0.01, \S P<0.005, \S \S P<5 \times 10^{-4}$ vs. WT controls; ${ }^{*} P<0.05$, 


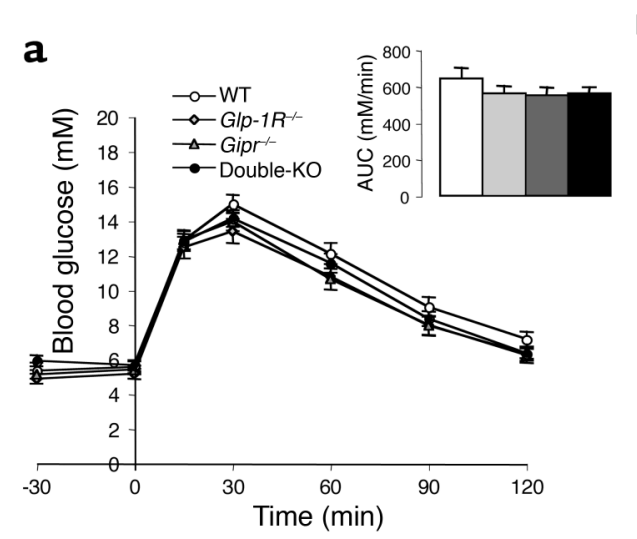

Males

b

Females
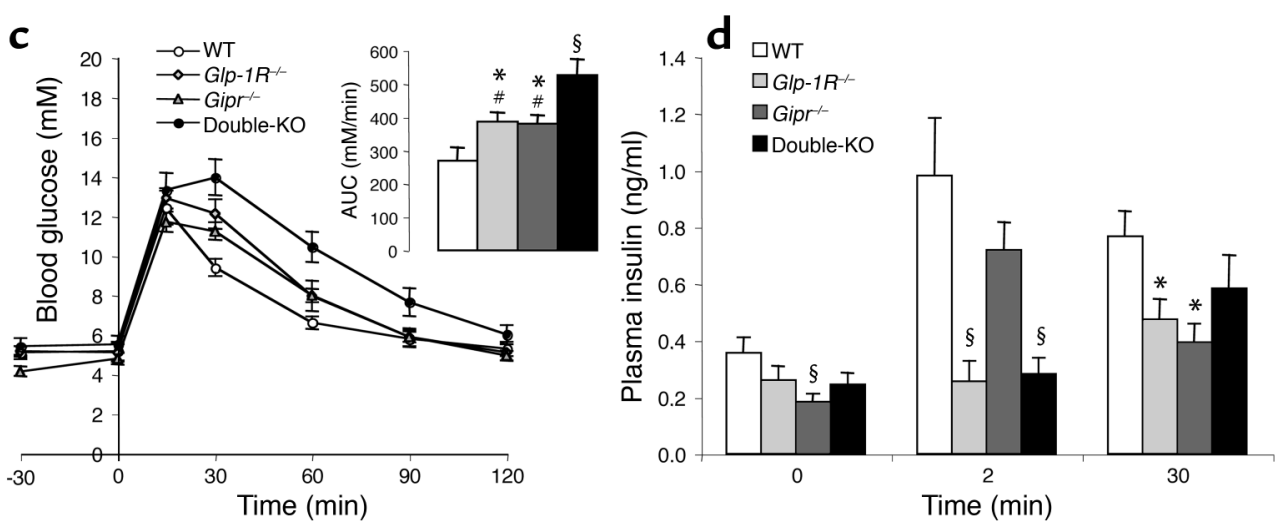

Figure 3

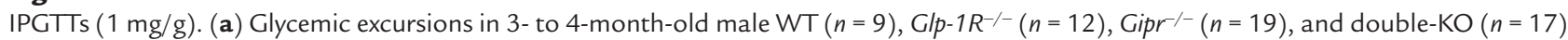
mice. Insets: quantification as AUC of the glycemic excursions. (b) Glycemic excursions in 10-month-old male WT $(n=6)$ and double$\mathrm{KO}(n=10)$ mice. Insets: quantification as AUC of the glycemic excursions. (c) Glycemic excursions in 3- to 4-month-old female WT ( $n=7)$, Glp-1R-/- $(n=11)$, Gipr ${ }^{\prime-}(n=9)$, and double-KO mice $(n=11)$. Insets: quantification as AUC of the glycemic excursions. (d) Plasma insulin levels in female mice at basal state and at 2 and 30 minutes after intraperitoneal glucose injection $(n=4-9)$. Data, pooled from two to four separate experiments, are expressed as means \pm SE. ${ }^{*} P<0.05, \S P<0.005$ vs WT controls. ${ }^{\#} P<0.05$ vs. double-KO.

single-KO mice had greater glycemic excursions after intraperitoneal glucose injection (AUC glucose $40-45 \%$ higher than in WT mice), and double-KO mice had still higher AUC glucose, approximately twice that of WT and $40 \%$ higher than single-KO mice (Figure $3 \mathrm{c}$ ).

Glucose intolerance in single- and double-KO female mice was associated with changes in plasma insulin concentration (Figure 3d). Remarkably, the 2-minute plasma insulin peak, which represents first-phase insulin secretion, was totally absent in the double-KO mice as well as in mice lacking the GLP-1 receptor, but was present in the Gipr-- mice (Figure 3d). The 30minute peak insulin levels were significantly reduced in the single-KO mice, but the reduction was not statistically significant in the double-KO mice (Figure $3 \mathrm{~d}$ ).

To evaluate whether glucose intolerance could be associated with peripheral insulin resistance, we performed hyperinsulinemic euglycemic clamp experiments in double-KO and WT female mice. Insulin was infused at either high $(18 \mathrm{U} / \mathrm{kg} / \mathrm{min})$ or intermediate $(6 \mathrm{U} / \mathrm{kg} / \mathrm{min})$ rates. In both conditions, double-KO mice had normal insulin sensitivity compared to WT mice, as revealed by identical glucose infusion rates to maintain euglycemia $(84.1 \pm 6.4$ vs. $75.5 \pm 5.4 \mathrm{mg} / \mathrm{kg} / \mathrm{min}$ in double-KO and control mice, respectively, at high insulin infusion rate, and $60.5 \pm 3.4$ vs. $60.1 \pm 6.0 \mathrm{mg} / \mathrm{kg} / \mathrm{min}$, in double-KO and control mice, respectively, at intermediate insulin infusion rate; $n=5-6$ ).

Analysis of insulin secretion in the perfused pancreas. To determine the insulin-secretory capacity of the endocrine pancreas of the mutant mice, we first performed pancreas perfusion experiments. In our setting, the pancreas is still connected to the duodenum and has normal connections to the local autonomic nervous system. Moreover, the hepatoportal glucose sensor should be exposed to the perfusate, which is introduced via the aorta (30). Glucose-induced insulin secretion in perfused pancreata from control female mice showed a strong first-phase secretion (Figure 4, a and d). Perfusion of pancreata from GIP-receptor KO mice showed a first phase of secretion that was not significantly different from that of control pancreas (Figure 4, a and d). In contrast, as compared to WT pancreas, Glp-1 $1 R^{-/-}$and double-KO pancreas perfusions revealed a markedly blunted first phase of insulin secretion (50 \pm 7 vs. $17 \pm 7$ and $11 \pm 3$ in control vs. $G l p-1 R^{-/}$and double-KO pancreata, respectively, Figure 4, 

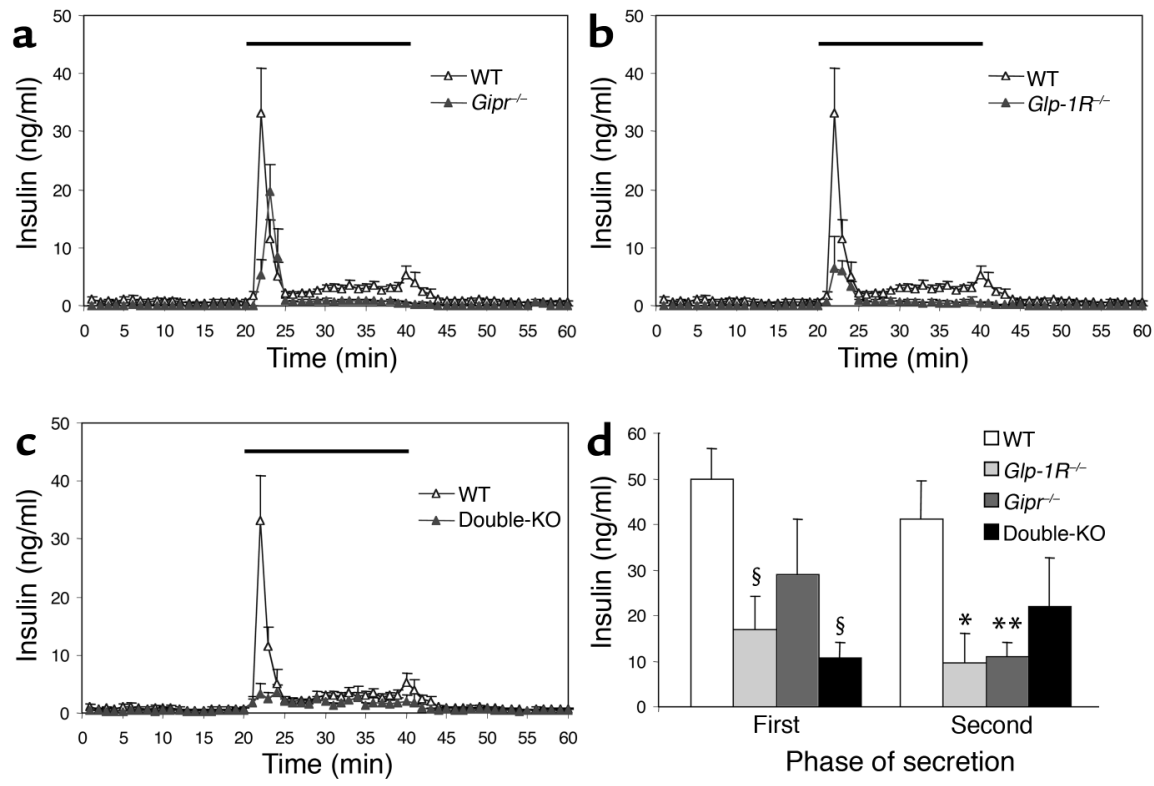

Figure 4

Glucose-induced insulin secretion in perfused pancreata from (a) Gipr ${ }^{-1}(n=4),(\mathbf{b})$ Glp-1 $1 R^{-1-}(n=4)$, and (c) double-KO $(n=4)$ mice compared to WT mice $(n=6)$. Pancreata were perfused with basal solution ( 1 $\mathrm{mM}$ glucose) for 30 minutes before perfusate was collected (from time 0 ) for analysis of secreted insulin. Glucose concentration was increased to $16.7 \mathrm{mM}$ for the indicated period (dark line). (d) Quantification of AUC of first-phase (minutes 21-25) and second-phase (minutes 26-45) insulin secretion. Data are presented as means \pm SEM of four to six separate experiments. ${ }^{*} P<0.05,{ }^{*} P<0.01, \S P<0.005$ when mutant mouse results were compared to those of the WT. b-d). The second phase of insulin secretion was significantly decreased in single-KO but not in double-KO pancreata, similar to the observation on second-phase secretion in IPGTTs. Notably, those defects occurred despite normal pancreatic insulin contents in single- and double-KO mice (Table 2). The excellent correlation between these results and those from the IPGTT indicate that the factors responsible for the loss of first-phase insulin secretion in the double-KO and GLP-1 receptor-KO mice remain in the perfused-pancreas setup.

Double-KO pancreatic islets exhibit impaired insulin secretion. We next evaluated the kinetics of insulin secretion in isletperifusion experiments. Figure 5a shows insulin secretion from control and single-KO islets when glucose concentration was raised to 11.1 or $16.7 \mathrm{mM}$. The kinetics of secretion in single- $\mathrm{KO}$ islets was indistinguishable from that of control islets, with a very rapid onset of secretion at high glucose concentration and suppression of secretion when glucose levels returned to basal values. Although there was no clear separation of first- and second-phase insulin secretion in the present experiments, as is usually the case in mouse islets (33), the initial rapid secretory response over the first 5 minutes of high-glucose perfusion is considered to represent the first phase of insulin secretion. The total amount of insulin released from single-KO islets was indistinguishable from those of control islets at 11.1 or $16.7 \mathrm{mM}$ glucose (Figure 5c). Moreover, as shown in Figure 5d, the ratio of insulin to DNA content of the different types of islets was identical.

Perifusion of double-KO islets (Figure $5 \mathrm{~b}$ ) revealed a pattern of insulin secretion characterized by a rapid initiation of secretion

\section{Table 2}

Pancreatic insulin content over the first 5 minutes of high-glucose perifusion, suggesting a normal first phase of insulin release. However, this secretion was of reduced amplitude, and the total amount of secreted insulin from the double-KO islets was markedly reduced (Figure 5c) despite a normal islet insulin/DNA ratio (Figure $5 \mathrm{~d}$ ).

To evaluate whether the secretory defect in double$\mathrm{KO}$ islets occurred upstream or downstream of the depolarization event, we stimulated insulin secretion by $\mathrm{K}^{+}$-induced depolarization. Figure $5 \mathrm{e}$ shows a markedly reduced secretory response to $\mathrm{K}^{+}$in double$\mathrm{KO}$ mice, strongly suggesting that there is a major defect distal to plasma membrane depolarization.

The above data thus demonstrate that in the absence of a single hormone receptor, first-phase and total insulin secretion were normal. In the absence of both receptors, onset of secretion was kinetically normal but total secretion was markedly reduced and associated with a defect in glucose signaling at a step distal to plasma membrane depolarization. This defect could result from reduced intracellular cAMP levels, to a defect in the insulin-secretory pathway as a consequence of alterations in the expression of genes controlling exocytosis of insulin granules, or both.

\begin{tabular}{|c|c|c|c|c|}
\hline & WT & 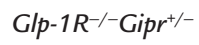 & - Gipr ${ }^{-1-G} / p-1 R^{+/-}$ & Double-KO \\
\hline \multicolumn{5}{|l|}{ creas (males) } \\
\hline lin/body weight ( $\mathrm{mU} / \mathrm{g})$ & $29.6 \pm 2.4(9)$ & $36.1 \pm 2.5(8)$ & $34.0 \pm 3.9(8)$ & $35.3 \pm 2.5(10)$ \\
\hline lin/pancreas (mU/mg) & $3.45 \pm 0.32(9)$ & $4.5 \pm 0.40(8)$ & $4.59 \pm 0.59(8)$ & $4.93 \pm 0.3(10)^{A}$ \\
\hline \multicolumn{5}{|l|}{ creas (females) } \\
\hline ulin/body weight $(\mathrm{mU} / \mathrm{g})$ & $57.5 \pm 3.3(8)$ & $52.9 \pm 2.5(5)$ & $53.1 \pm 2.6(7)$ & $48.7 \pm 2.6(9)^{\mathrm{B}}$ \\
\hline lin/pancreas $(\mathrm{mU} / \mathrm{mg})$ & $6.6 \pm 0.4(8)$ & $6.4 \pm 0.3(5)$ & $6.0 \pm 2.3(7)$ & $6.2 \pm 0.3(9)$ \\
\hline
\end{tabular}

Numbers of experimental animals are given in parentheses. ${ }^{A} P<0.005,{ }^{B} P<0.05$ vs. WT mice. 

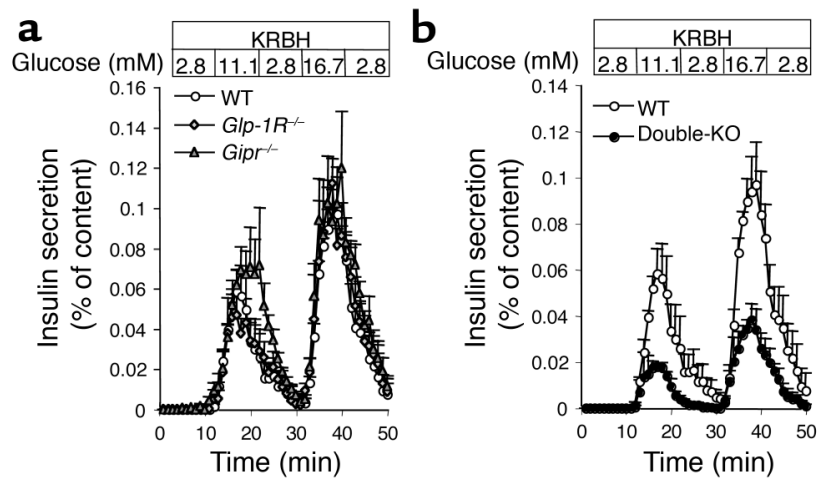

c
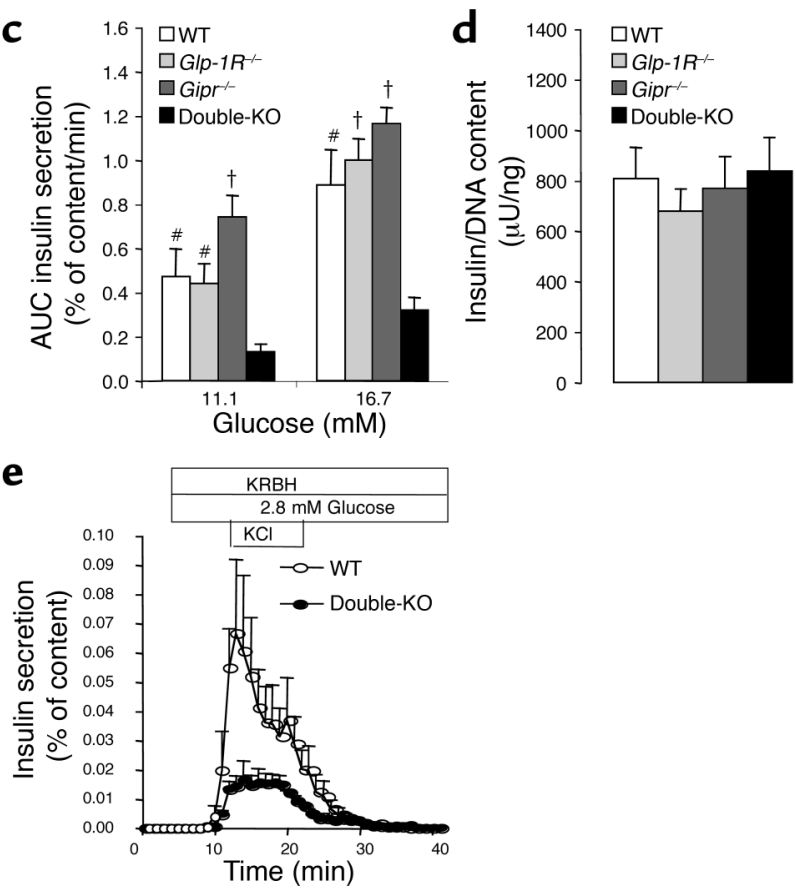

To distinguish between these alternatives, we first tested whether the secretory defect was observed when the perifusion experiments were performed in the presence or absence of IBMX combined or not combined with forskolin. As shown in Figure 6a, the secretory response to $16.7 \mathrm{mM}$ glucose was similarly reduced in double-KO islets whether IBMX was included in the perifusate or not. Moreover, the addition of forskolin in the presence of IBMX strongly stimulated insulin secretion in response to $16.7 \mathrm{mM}$ glucose, and the insulin secretion rate was similar in double-KO and control islets (Figure 6b). In Figure 6, c and d, in static incubations, we measured insulin secretion from control and double- $\mathrm{KO}$ islets and their intracellular cAMP levels. The results show that secretion from double-KO islets incubated with or without IBMX was markedly reduced as compared to secretion from control islets. Furthermore, addition of forskolin to the incubation medium strongly increased secretion in both control and double-KO islets, and secretion was quantitatively identical from both types of islets. These results are similar to those obtained in perifusion experiments (see Figure 6, a and b). The intracellular cAMP levels from islets incubated in the presence of 16.7

\section{Figure 5}

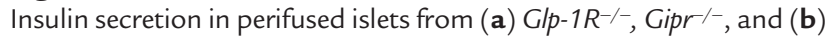
double-KO mice compared with WT mice. (c) Quantification as AUC of insulin responses shown in $\mathbf{a}$ and $\mathbf{b} . n=4$. Data are expressed as means \pm SE of insulin secretion normalized to the insulin content of

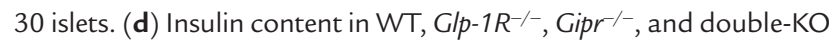
isolated islets. Data are expressed as insulin content normalized to the DNA content in 30 islets. $n=5-10$. (e) Insulin secretion in WT and double-KO islets perifused with $2.8 \mathrm{mM}$ glucose $+30 \mathrm{mM} \mathrm{KCl}$. Data are expressed as means \pm SE of insulin secretion normalized to the insulin content of 30 islets. $n=3 .{ }^{\#} P<0.05,{ }^{\dagger} P<0.005$ vs. double-KO.

$\mathrm{mM}$ glucose and IBMX were identical in control and double-KO islets (Figure 6d), suggesting that the difference in cAMP levels cannot explain the reduced secretory activity in the mutant islets. In the presence of forskolin and IBMX, cAMP levels were strongly elevated in both types of islets (Figure $6 \mathrm{~d}$ ), conditions in which insulin secretion was normalized in double-KO islets (Figure 6c). Together, these data suggest that impaired insulin secretion in double-KO islets was not due to lower cAMP levels but rather to a reduced sensitivity to this second messenger.

To evaluate whether the secretory defect was restricted to cAMP-controlled mechanisms, we performed islet-perifusion experiments in the presence or absence of carbachol. As shown in Figure 6e, the secretory defect observed in double-KO islets perifused with high glucose concentrations was suppressed when the islets were perifused in the presence of carbachol, an activator of the G-coupled muscarinic receptors.

Despite their secretory defect, double-KO islets exhibited no obvious abnormality in insulin content (Table 2), size range, gross morphology, and distribution of insulin- and glucagon-producing cells (data not shown). Hence, double-KO islets have a $\beta$ cell autonomous defect in stimulated insulin secretion that is probably due to the absence of both GLP-1- and GIPreceptor signaling. However, strikingly, first-phase insulin secretion was not suppressed in GLP-1 receptor $\mathrm{KO}$ islets and only moderately in double- $\mathrm{KO}$ islets. This suggests that the blunted first-phase insulin secretion obtained via IPGTT and in the perfused pancreas may reflect an integrative response, including glucose sensors located outside the endocrine pancreas.

The first phase of insulin secretion is inhibited when the hepatoportal sensor is inactivated. We and others previously demonstrated that a glucose sensor was located in the hepatoportal vein region. This sensor controls insulin secretion, through autonomic nervous connections (34). Using different mouse models, we demonstrated that this sensor required GLUT2 gene expression and the presence of an activated GLP-1 receptor $(20,21)$ for normal function. Our present data suggest that this sensor could be involved in the control of first-phase insulin secretion, since GLP-1 receptor KO mice lack first-phase secretion during an IPGTT and in perfused pancreata but not in perifused isolated islets.

Thus, to test the involvement of the hepatoportal sensor in the control of first-phase insulin secretion, we per- 

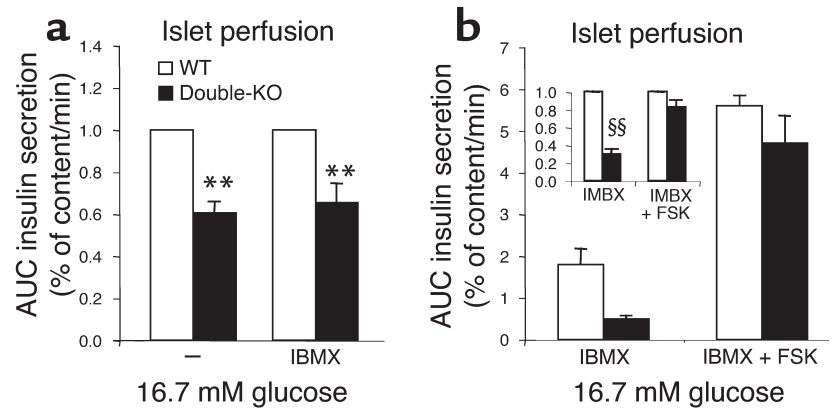

$16.7 \mathrm{mM}$ glucose

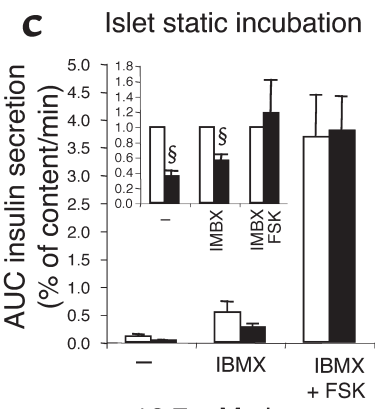

$16.7 \mathrm{mM}$ glucose
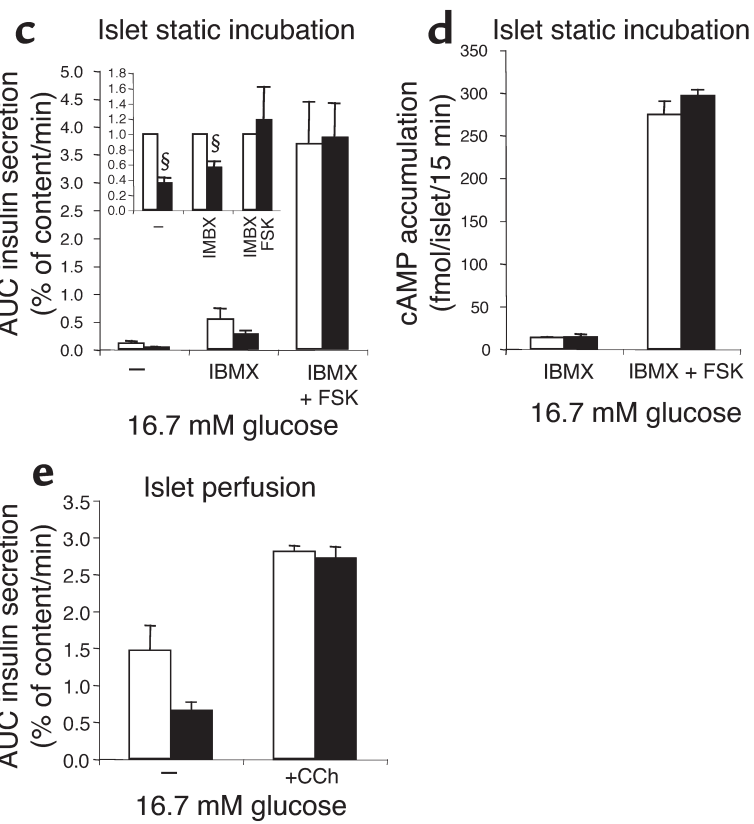

formed two sets of experiments. First, we measured insulin secretion in RipGlut1Glut $2^{-1-}$ mice. These mice have a nonfunctional hepatoportal sensor due to GLUT2 gene inactivation; however, they have normal biphasic glucose-stimulated insulin secretion, as assessed in isletperifusion experiments, due to the transgenic expression of a GLUT1 transporter in their $\beta$ cells (33). Figure 7a shows that the 2-minute peak of plasma insulin normally induced by an intraperitoneal glucose injection was absent from RipGlut1Glut2-/- mice. Similarly, when evaluated in the perfused pancreas, this first peak of insulin secretion was almost completely blunted (Figure $7 b$ ).

In a second set of experiments, we inactivated the hepatoportal glucose sensor in control mice by portal vein infusion of the GLP-1 receptor antagonist exendin(9-39). The perfusion rate was chosen so as to block the function of the hepatoportal sensor without interfering with blood glucose levels $(0.5 \mathrm{pmol} / \mathrm{kg} / \mathrm{min})$, as previously described (21). Thirty minutes after initiation of the perfusion experiments, mice were injected intraperitoneally with glucose. Figure $7 \mathrm{c}$ shows the glycemic profiles over the time course of the experiments, and Figure $7 \mathrm{~d}$ shows the plasma insulin levels measured at time 0 , at the initiation of peptide or saline infusion (time 60 minutes), and 2 and 15 minutes (time 92 and 105 min-

\section{Figure 6}

cAMP, carbachol, and insulin secretion. (a) IBMX and insulin secretion. Islets were perifused successively with $2.8 \mathrm{mM}$ glucose for $10 \mathrm{~min}$ utes, $16.7 \mathrm{mM}$ glucose for 10 minutes, $2.8 \mathrm{mM}$ glucose for $20 \mathrm{~min}$ utes, first in the absence and then in the presence of IBMX $100 \mu \mathrm{M}$. Shown are the AUCs of insulin responses normalized to WT values set at 1 . Absolute values of AUCs for WT are $0.32 \%$ of insulin content (without IBMX) and $0.99 \%$ of insulin content (with IBMX). (b) Forskolin and insulin secretion. Islets were perifused in the presence of $100 \mu \mathrm{M}$ IBMX as follows: $2.8 \mathrm{mM}$ glucose for 10 minutes, $16.7 \mathrm{mM}$ glucose for 10 minutes, $2.8 \mathrm{mM}$ glucose for 20 minutes, $16.7 \mathrm{mM}$ glucose + forskolin $(10 \mu \mathrm{M})$ for 10 minutes, and $2.8 \mathrm{mM}$ glucose for 25 minutes. Results are AUCs of insulin responses $(n=4)$. Inset: doubleKO values normalized to WT values, set at 1 . (c) Static incubations of isolated islets. Insulin secretion from 10 islets incubated for 15 minutes at $16.7 \mathrm{mM}$ glucose in the presence or absence of IBMX $100 \mu \mathrm{M}$ and forskolin (FSK) $10 \mu \mathrm{M}$ ( $n=3$ separate experiments). Inset, double$K O$ values normalized to WT values, set at 1 . (d) cAMP accumulation in 20 islets incubated in presence of IBMX $250 \mu \mathrm{M}$ with or without forskolin $10 \mu \mathrm{M}$ ( $n=4-9$, pooled from two separate experiments). Data are expressed as means \pm SE of femtomoles CAMP accumulated per islet during 20 minutes. ${ }^{*} P<0.01, \S P<0.005, \S \S P<0.001$ vs. WT controls. (e) Carbachol and insulin secretion. Islets were perifused with $16.7 \mathrm{mM}$ glucose in the presence or absence of carbachol (Cch, $1 \mu \mathrm{M})$. The data are AUCs of secreted insulin. Data are mean $\pm \operatorname{SEM}(n=3)$.

utes) after the injection of glucose. The basal insulinemic levels ( 0 and 60 minutes) were similar in the salineand antagonist-perfused mice. The first peak of insulin secretion $(2$ minutes after glucose injection, time 92 minutes) reached $75 \pm 11 \mu \mathrm{U} / \mathrm{ml}$ for the saline-infused mice and $30 \pm 2 \mu \mathrm{U} / \mathrm{ml}$ for the exendin-(9-39)-infused mice. Fifteen minutes after injection (time 105 minutes), the plasma insulin concentrations were reduced to the same level in both groups. Thus, the above data demonstrate that inhibition of the hepatoportal glucose sensor by GLUT2 gene inactivation or exendin- $(9$ 39) portal infusion dramatically reduced first peak insulin secretion after intraperitoneal glucose injection.

\section{Discussion}

The present study revealed that the gluco-incretin hormones GIP and GLP-1 control glucose homeostasis and insulin secretion through multiple mechanisms.

Insulinotropic effect and glucose tolerance tests. After oral glucose administration, the glycemic excursions were observed to be increased in single-receptor $\mathrm{KO}$ as compared to control mice and to be even higher in double$\mathrm{KO}$ mice. This was associated with correspondingly lower plasma insulin levels measured 15 minutes after the glucose loads. These data are best explained by the additive effect of GIP and GLP-1, secreted by gut endocrine cells after glucose absorption, and whose insulinotropic action requires binding to their cognate receptors at the $\beta$ cell surface. This interpretation is also in agreement with the data (Figure 1c) showing suppressed insulinotropic action of these hormones on the islets isolated from the single- and double-KO mice. Also notable are the normal basal glycemic levels observed in the double-KO mice. Indeed, one of the initial reasons to 
a

$\square$ WT
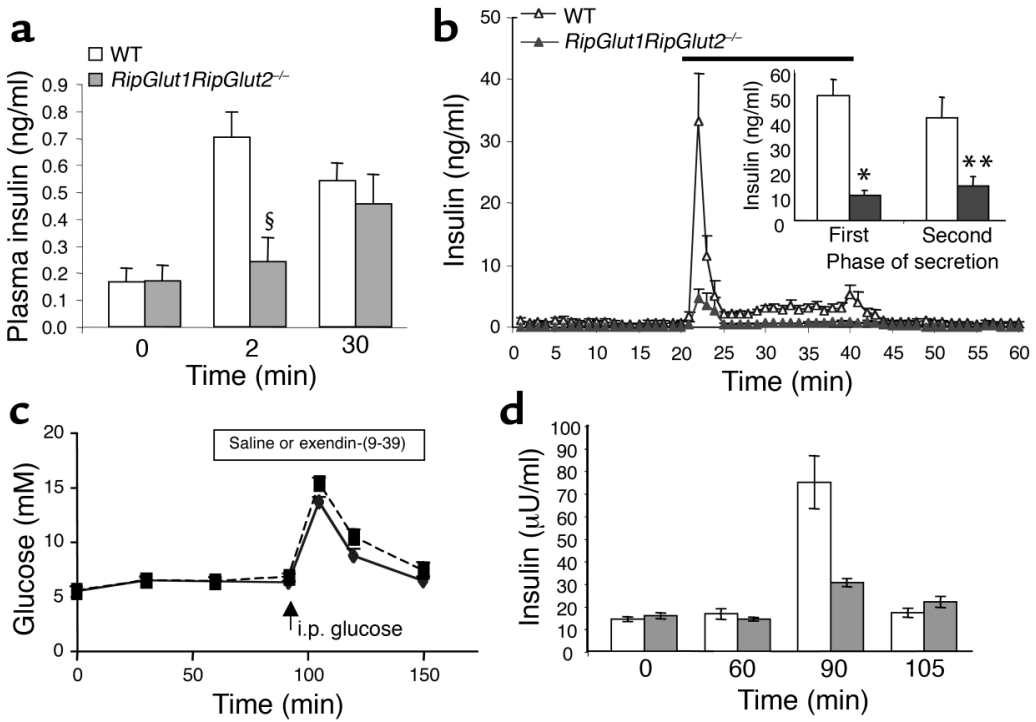

d

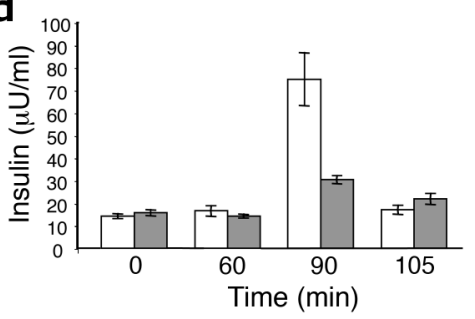

\section{Figure 7}

Glucose-induced insulin secretion in RipGlut1Glut2 ${ }^{-1-}$ female mice. (a) IPGTTs (1 mg/g) in RipGlut1Glut2 ${ }^{-1-}$ compared to C57BL/6J WT mice $(n=7)$. $\$ P<0.005$. (b) Glucoseinduced insulin secretion in perfused pancreata of RipGlut1Glut2 ${ }^{-/-}(n=4)$ compared to WT mice $(n=6)$. Pancreata were perfused as described in Figure $4(\mathbf{b}$, inset). Quantification of the AUCs corresponding to first- and second-phase insulin secretion from pancreata ofWT (white bars) and RipGlut1Glut2-/- (gray bars) mice. Data are presented as means \pm SEM from four to six separate experiments. ${ }^{*} P<0.001,{ }^{*} P<0.04$, for mutant vs. WT mice. (c) Glycemic profiles of control mice infused through the portal vein, between 60 and 150 minutes (open bar at the top), with saline (diamonds) or exendin(9-39) $(0.5 \mathrm{pmol} / \mathrm{kg} / \mathrm{min}$, squares) and receiving an intraperitoneal (i.p.) glucose injection $(1 \mathrm{mg} / \mathrm{g}$ ) at 90 minutes (arrow, i.p. glucose). The glycemic profiles were similar in the two groups. (d) Plasma insulin levels for the experiment presented in c. Basal ( 0 and 60 minutes) insulin levels were similar in both groups of mice. First peak of insulin secretion (92 minutes) was, however, strikingly reduced in exendin-(9-39)-infused mice. Plasma insulin levels at 105 minutes (i.e., 15 minutes after glucose injection) were similar in both groups of mice. These data demonstrate that inhibition of the hepatoportal vein glucose sensor significantly blunts first-phase insulin secretion after intraperitoneal glucose injection. Data are mean \pm SEM with $n=7$ and $n=5$ for saline- and exendin-(939)-infused mice, respectively.

generate and study these mice was to evaluate whether suppression of both gluco-incretin hormone receptors would lead to a more pronounced defect in glucose homeostasis as compared with single-receptor gene inactivation. However, the present data demonstrate that suppression of the action of both hormones does not lead to a diabetic phenotype, indicating that even if the insulinotropic action of these hormones is very powerful, their physiological role is not critical for normal glucose homeostasis. Their role may nevertheless become more important when the organism is faced with more challenging conditions, such as high-fat or high-carbohydrate diet feeding, as reported for the Gipr/- mice (22).

Insulin secretion in vivo and extra-islet glucose sensors. Intraperitoneal glucose injections revealed mild intolerance in female mice with single-receptor gene inactivation and a more severe intolerance in the double-KO mice. Intolerance was the result of a defect in insulin secretion and not of a decreased sensitivity to insulin action as assessed by hyperinsulinemic clamp studies.
The defects in insulin secretion observed during intraperitoneal glucose injections were twofold. First, there was a reduction in the level of insulin observed at 30 minutes. This reduction was similar in both $\mathrm{Gipr}^{-1}$ and $G l p-1 R^{-/-}$mice. In double-KO mice, the reduction at 30 minutes did not reach statistical significance. While the reason for this lack of significant reduction is not known, it may suggest the presence of compensatory mechanisms enhancing insulin secretion when both receptors are inactivated. Second, first-phase secretion, measured as the 2-minute plasma insulin peak, was absent in Glp-1 $R^{-/-}$and double-KO mice but present in control and $\mathrm{Gipr}^{-}$ mice. These patterns of first and second peak of insulin secretion were strikingly similar when tested in the perfused pancreas. In our experimental setting, the pancreas is perfused in situ from the aorta-that is, with all its anatomical connections preserved, including those to the local autonomic nervous network and to the stimulated hepatoportal glucose sensor.

In perifusion experiments, although we usually do not observe clear separation between the first and second phase of secretion, we consider the strong secretory response over the first 5 minutes of glucose stimulation to be the first phase. This first phase is, for instance, lost in Glut $2^{--}$islets, whereas a second phase, which starts a few minutes later, is still detected (35). Here, first-phase secretion in islets from single-receptor $\mathrm{KO}$ mice was kinetically and quantitatively normal. In double-receptor KO islets, initiation of insulin secretion displayed a normal kinetics, but the amplitude of this first peak was decreased. Thus the defect in first-phase secretion described in vivo and in the perfused pancreas was not observed when studying isolated islets.

What could explain the absence of first-phase insulin

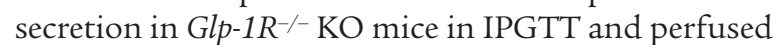
pancreas experiments when it is present in the perifused islets? We know from our previous studies that the GLP1 receptor is also present in extrapancreatic glucose sensors, in particular those present in the hepatoportal vein area (21). This sensor controls several physiological functions, including the stimulation of insulin secretion through an autonomic nervous system pathway (34). We have demonstrated that the function of this sensor is suppressed when the GLP-1 receptor is absent, as in

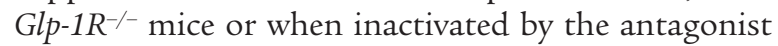
exendin-(9-39). It has also been reported that the hepato- 
portal sensor was not sensitive to GIP (36). We have obtained direct evidence that inhibiting the hepatoportal sensor in control mice by exendin-(9-39) portal vein infusion strongly reduced the first peak of insulin secretion during an IPGTT. This first peak was not completely suppressed, however, indicating either that there was a partial pharmacological blockade or that other sensors, possibly related to glucose-sensitive nervous fibers of the enteric nervous system, play a role in controlling firstphase secretion, or a combination of both.

Further support for the hypothesis that the hepatoportal sensor contributes to the triggering of first-phase secretion was obtained by studying RipGlut1Glut2-/mice. These mice have no endogenous GLUT2 gene but express a transgenic GLUT1 in their $\beta$ cells that normalizes the kinetics of insulin secretion as assessed in isletperifusion experiments (33). However, the hepatoportal sensor of these mice is no longer functional in the absence of GLUT2 (20). Strikingly, first-phase insulin secretion was absent during an intraperitoneal glucose challenge or in perfused pancreas experiments. Thus, inactivation of the hepatoportal sensor, or of a similar sensor present outside of the endocrine pancreas, also leads to suppression of in vivo first-phase insulin secretion. Kirchgessner and co-workers have also demonstrated that neurons from the enteric nervous system located in the pancreas are glucose responsive and express the $\mathrm{K}_{\text {ATP }}$ channels (37), implying a role in glucose signaling. These sensors may be activated during the pancreas-perfusion experiments.

These results thus suggest that glucose sensors located outside the endocrine pancreas participate in the control of in vivo first-phase insulin secretion. These sensors are probably connected to the pancreatic $\beta$ cells through the autonomic or enteric nervous system. The hepatoportal sensor, in particular, may be one of the early glucose detectors involved. Indeed, its location in the portal vein, where ingested glucose first transits, may be ideal for a rapid stimulation of insulin secretion.

These sensors show similarities with pancreatic $\beta$ cells by expressing key molecules involved in glucose sensing. Because of their role in the control of the first phase of insulin secretion, the disappearance of which is an early sign of diabetes development, their dysfunction may represent an initial pathogenic event.

Islet-perifusion studies. Islet-perifusion studies also revealed a striking reduction in the rate of insulin secretion from double-KO islets. This occurred even though islet morphology and insulin content were normal. Our data demonstrated that a major defect was at a step distal to membrane depolarization, since perifusion of islets in high concentrations of $\mathrm{K}^{+}$led to a much weaker secretory response as compared with control islets. This suggests a defect in either $\mathrm{Ca}^{2+}$ entry or the mechanisms controlling exocytosis of insulin granules.

The decreased secretory response to high glucose concentrations and IBMX of double-KO as compared to control islets could not be due to reduced intracellu- lar cAMP levels. Indeed, in these stimulatory conditions the cAMP levels were identical in both types of islets. However, addition of forskolin, which strongly increased the intracellular cAMP levels, led to similar rates of secretion from both types of islets.

The second messenger cAMP acts via two pathways in $\beta$ cells: first, by activation of protein kinase $A$, which phosphorylates GLUT2, the $\mathrm{K}_{\mathrm{ATP}}$ and $\mathrm{Ca}^{2+}$ channels (38-40), and as yet unidentified substrates; and second, by binding to the CAMP sensor protein CAMPGEF2 or Epac2, which forms a complex with Rim2 and activates Rab3, a component of the exocytotic machinery $(41,42)$. Affinity for cAMP of protein kinase $\mathrm{A}$ is in the nanomolar range (43), whereas it is in the micromolar range for cAMP-GEF2 (41). Thus, the defect in secretion observed at low intracellular cAMP levels may be due to a selective defect in the protein kinase $A$ pathway that would be overcome by the stimulation of the cAMP-GEF2-Rim2 pathway when intracellular cAMP levels are strongly increased by forskolin. An additional effect of forskolin could nevertheless also be on the blockade of Kv channels (44), which would increase insulin secretion (45).

The defect in protein kinase A action may result from a decreased expression of protein targets whose expression are under the control of the GIP and GLP-1 receptors. Indeed, stimulation of GLP-1 and GIP receptors not only potentiates insulin secretion but also stimulates the proliferation and differentiation of pancreatic $\beta$ cells as well as the expression of $\beta$ cell genes such as $P d x-1$, proinsulin, Glut2, and glucokinase. GLP-1 and GIP receptors increase gene transcription via activation of cAMP-responsive elements binding proteins (46) but possibly also through the MAPK pathway (47). Finally, since carbachol stimulation led to the same rate of glucose-induced secretion in control and double-KO islets, this further supports the suggestion that there is a specific downregulation of cAMP-regulated proteins and not a general defect in the secretory machinery.

In summary, our study demonstrates the additive effect of gluco-incretin hormones in the stimulation of insulin secretion after oral glucose absorption. Permanent absence of both gluco-incretin hormone receptors led to glucose intolerance in female mice due to a defect in insulin secretion with no impairment of insulin sensitivity. GLP-1 receptor expression, at glucose sensors located outside the endocrine pancreas, was shown to be required for the in vivo control of first-phase insulin secretion. Finally, inactivation of both incretin hormone receptors induced a $\beta$ cell autonomous defect in stimulated insulin secretion; a major part of this defect is located at a site distal to plasma membrane depolarization. The altered expression of genes implicated in the control of insulin exocytosis may underlie the latter defect. Future studies will be required to identify these genes. These may represent important effectors of gluco-incretin hormone action and may be involved in the pathogenesis of type 2 diabetes. 


\section{Acknowledgments}

We thank Wanda Dolci, Montserrat Gonzalez, and Olivier Dupont for expert technical assistance, and P. Kopp and J.-F. Spetz (Friedrich Miescher Institute) for technical assistance in generating the $\mathrm{Gipr}^{-/}$mice. This work was supported by grants of the Swiss National Science Foundation to B. Thorens and C.B. Wollheim. I. Franklin was supported by the European Commission (HPRN-CT-2000-00082).

1. Ebert, R., and Creutzfeldt, W. 1987. Gastrointestinal peptides and insulin secretion. Diabetes Metab. Rev. 3:1-16.

2. Creutzfeldt, W., and Nauck, M. 1992. Gut hormones and diabetes mellitus. Diabetes Metab. Rev. 8:149-177.

3. Mojsov, S., Weir, G.C., and Habener, J.F. 1987. Insulinotropin: glucagonlike peptide 1 (7-37) co-encoded in the glucagon gene is a potent stimulator of insulin release in the perfused rat pancreas. J. Clin. Invest. 79:616-619.

4. Weir, G.C., Mojsov, S., Hendrick, G.K., and Habener, J.F. 1989. Glucagonlike peptide 1 (7-37) actions on endocrine pancreas. Diabetes. 38:338-342.

5. Thorens, B. 1992. Expression cloning of the pancreatic beta cell receptor for the gluco-incretin hormone glucagon-like peptide I. Proc. Natl. Acad. Sci. U.S.A. 89:8641-8645.

6. Usdin, T.B., Mezey, E., Button, D.C., Brownstein, M.J., and Bonner, T.I. 1993. Gastric inhibitory polypeptide receptor, a member of the secretinvasoactive intestinal peptide receptor family, is widely distributed in peripheral organs and the brain. Endocrinology. 133:2861-2870.

7. Nauck, M., Stöckmann, F., Ebert, R., and Creutzfeldt, W. 1986. Reduced incretin effect in type 2 (non-insulin-dependent) diabetes. Diabetologia. 29:46-52.

8. Holst, J.J., Gromada, J., and Nauck, M.A. 1997. The pathogenesis of NIDDM involves a defective expression of the GIP receptor. Diabetologia. 40:984-986.

9. Gutniak, M., Orskov, C., Holst, J.J., Ahrén, B., and Efendic, S. 1992. Antidiabetogenic effect of glucagon-like peptide-1 (7-36) amide in normal subjects and patients with diabetes mellitus. N. Engl. J. Med. 326:1316-1322.

10. Holst, J.J. 2002. Therapy of type 2 diabetes mellitus based on the actions of glucagon-like peptide-1. Diabetes Metab. Res. Rev. 18:430-441.

11. Zander, M., Madsbad, S., Madsen, J.L., and Holst, J.J. 2002. Effect of 6week course of glucagon-like peptide 1 on glycaemic control, insulin sensitivity, and $\beta$ cell function in type 2 diabetes: a parallel-group study. Lancet. 359:824-830.

12. Stoffers, D.A., et al. 2000. Insulinotropic glucagon-like peptide 1 agonists stimulate expression of homeodomain protein IDX-1 and increase islet size in mouse pancreas. Diabetes. 49:741-748.

13. Xu, G., Stoffers, D.A., Habener, J.F., and Bonner-Weir, S. 1999. Exendin4 stimulates both $\beta$-cell replication and neogenesis, resulting in increased $\beta$-cell mass and improved glucose tolerance in diabetic rats. Diabetes. 48:2270-2276

14. Wang, Y., et al. 1995. Glucagon-like peptide-1 affects gene transcription and messenger ribonucleic acid stability of components of the insulin secretory system in RIN 1046-38 cells. Endocrinology. 136:4910-4917.

15. Drucker, D.J., Philippe, J., Mojsov, S., Chick, W.L., and Habener, J.F. 1987. Glucagon-like peptide I stimulates insulin gene expression and increases cyclic AMP levels in rat islet cell line. Proc. Natl. Acad. Sci. U. S. A. 84:3434-3438

16. Tourrel, C., et al. 2002. Persistent improvement of type 2 diabetes in the Goto-Kakizaki rat model by expansion of the $\beta$-cell mass during the prediabetic period with glucagon-like peptide-1 or exendin-4. Diabetes. 51:1443-1452.

17. Li, Y., et al. 2003. Glucagon-like peptide-1 receptor signaling modulates beta cell apoptosis. J. Biol. Chem. 278:471-478.

18. Burcelin, R., Dolci, W., and Thorens, B. 2000. Portal glucose infusion in the mouse induces hypoglycemia. Evidence that the hepatoportal glucose sensor stimulates glucose utilization. Diabetes. 49:1635-1642.

19. Burcelin, R., et al. 2003. GLUT4, AMP kinase, but not the insulin receptor, are required for hepatoportal glucose sensor-stimulated muscle glucose utilization. J. Clin. Invest. 111:1555-1562. doi:10.1172/JCI200316888.

20. Burcelin, R., Dolci, W., and Thorens, B. 2000. Glucose sensing by the hepatoportal sensor is GLUT2-dependent. In vivo analysis in GLUT2null mice. Diabetes. 49:1643-1648.

21. Burcelin, R., DaCosta, A., Drucker, D., and Thorens, B. 2001. Glucose competence of the hepatoportal vein sensor requires the presence of an activated glucagons-like peptide-1 receptor. Diabetes. 50:1720-1728.
22. Miyawaki, K., et al. 1999. Glucose intolerance caused by a defect in the entero-insular axis: a study in gastric inhibitory polypeptide receptor knockout mice. Proc. Natl. Acad. Sci. U.S.A. 96:14843-14847.

23. Miyawaki, K., et al. 2002. Inhibition of gastric inhibitory polypeptide signaling prevents obesity. Nat. Med. 8:738-742.

24. Scrocchi, L.A., et al. 1996. Glucose intolerance but normal satiety in mice with a null mutation in the glucagon-like peptide-1 receptor gene. Nat. Med. 2:1254-1258.

25. Flamez, D., et al. 1998. Mouse pancreatic $\beta$-cells exhibit preserved glucose competence after disruption of the glucagon-like peptide-1 receptor gene. Diabetes. 47:646-652.

26. Pamir, N., et al. 2003. Glucose-dependent insulinotropic polypeptide receptor null mice exhibit compensatory changes in the enteroinsular axis. Am. J. Physiol. Endocrinol. Metab. 284:E931-E939.

27. Pederson, R.A., et al. 1998. Enhanced glucose-dependent insulinotropic polypeptide secretion and insulinotropic action in glucagon-like peptide 1 receptor -/- mice. Diabetes. 47:1046-1052.

28. Gremlich, S., et al. 1995. Cloning, functional expression and chromosomal localization of the human pancreatic islet glucose-dependent insulinotropic polypeptide receptor. Diabetes. 44:1202-1208.

29. Shima, H., et al. 1998. Disruption of the $\mathrm{p} 70(\mathrm{~s} 6 \mathrm{k}) / \mathrm{p} 85(\mathrm{~s} 6 \mathrm{k})$ gene reveals a small mouse phenotype and a new functional S6 kinase. EMBO J. 17:6649-6659.

30. Shima, H., et al. 1998. Disruption of the $\mathrm{p} 70^{\mathrm{s} 6 \mathrm{k}} / \mathrm{p} 85^{\mathrm{s} 6 \mathrm{k}}$ gene reveals a small mouse phenotype and a new functional S6 kinase. EMBO J. 17:6649-6659.

31. Maechler, P., Gjinovci, A., and Wollheim, C.B. 2002. Implication of glutamate in the kinetics of insulin secretion in rat and mouse perfused pancreas. Diabetes. 51:S99-S102.

32. Gotoh, M., et al. 1987. Reproducible high yield of rat islets by stationary in vitro digestion following pancreatic ductal or portal venous collagenase injection. Transplantation. 43:725-730.

33. Thorens, B., Guillam, M.-T., Beermann, F., Burcelin, R., and Jaquet, M. 2000 . Transgenic reexpression of Glut 1 or Glut 2 in pancreatic $\beta$ cells rescues Glut2-null mice from early death and restores normal glucose-stimulated insulin secretion. J. Biol. Chem. 275:23751-23758.

34. Balkan, B., and Li, X. 2000. Portal GLP-1 administration in rats augments the insulin response to glucose via neuronal mechanisms. Am.J. Physiol. 279:R1449-R1454.

35. Guillam, M.-T., et al. 1997. Early diabetes and abnormal postnatal pancreatic islet development in mice lacking GLUT2. Nat. Genet. 17:327-330.

36. Nishizawa, M., Nakabayashi, H., Uchida, K., Nakagawa, A., and Niijima, A. 1996. The hepatic vagal nerve is receptive to incretin hormone glucagon-like peptide-1, but not to glucose-dependent insulinotropic polypeptide, in the portal vein. J. Auton. Nerv. Syst. 61:149-154.

37. Liu, M.-T., Seino, S., and Kirchgessner, A.L. 1999. Identification and characterization of glucoresponsive neurons in the enteric nervous system. J. Neurosci. 19:10305-10317.

38. Thorens, B., et al. 1996. Protein kinase A dependent phosphorylation of GLUT2 in pancreatic $\beta$ cells. J. Biol. Chem. 271:8075-8081.

39. Béguin, P., et al. 1999. PKA-mediated phosphorylation of the human $\mathrm{K}_{\mathrm{ATP}}$ channel: separate roles of Kir6.2 and SUR1 subunit phosphorylation. EMBOJ. 18:4722-4732.

40. Leiser, M., and Fleischer, N. 1996. cAMP-dependent phosphorylation of the cardiac-type a1 subunit of the voltage-dependent $\mathrm{Ca}^{2+}$ channel in a murine pancreatic $\beta$ cell line. Diabetes. 45:1412-1418.

41. Ozaki, N., et al. 2000. cAMP-GEFII is a direct target of cAMP in regulated exocytosis. Nat. Cell Biol. 2:805-811.

42. Kashima, Y., et al. 2001. Critical role of cAMP-GEFII-Rim2 complex in incretin-potentiated insulin secretion. J. Biol. Chem. 276:46046-46053.

43. Woodford, T.A., Correll, L.A., McKnight, G.S., and Corbin, J.D. 1989. Expression and characterization of mutant forms of the type I regulatory subunit of cAMP-dependent protein kinase. The effect of defective cAMP binding on holoenzyme activation. J. Biol. Chem. 264:13321-13328.

44. Matthias, K., Seifert, G., Reinhardt, S., and Steinhauser, C. 2002. Modulation of voltage-gated $\mathrm{K}(+)$ channels $\mathrm{Kv} 11$ and $\mathrm{Kv} 14$ by forskolin. Neuropharmacology. 43:444-449.

45. MacDonald, P.E., and Wheeler, M.B. 2003. Voltage-dependent $K(+)$ channels in pancreatic beta cells: role, regulation and potential as therapeutic targets. Diabetologia. 46:1046-1062.

46. Jhala, U.S., et al. 2003. cAMP promotes pancreatic beta-cells survival via CREB-mediated induction of IRS2. Genes Dev. 17:1575-1580.

47. Gomez, E., Pritchard, C., and Herbert, T.P. 2002. cAMP-dependent protein kinase and $\mathrm{Ca}^{2+}$ influx through $\mathrm{L}$-type voltage-gated calcium channels mediate raf-independent activation of extracellular regulated kinase in response to glucagon-like peptide- 1 in pancreatic $\beta$-cells. J. Biol. Chem. 277:48146-48151. 